\title{
Correspondence
}

\section{Rid Russian science of corruption}

Your claim that "Russian science is recovering" is not strictly true (Nature 477, 5; 2011). Although there has been a large influx of money into research recently, its distribution seems in many cases to have been overshadowed by allegations of corruption and power play.

Six mega-grant projects in high-energy physics, announced this summer by Prime Minister Vladimir Putin, were never subject to open scientific debate. Most of them will be managed by the Kurchatov Institute in Moscow, whose director, Mikhail Kovalchuk, belongs to Putin's 'inner circle' (Nature 453, 702 703; 2008). The Scientific Cadres federal programme, which is managed by the Ministry of Science and Education and is formally a competition, has deteriorated into a distribution of contracts in narrowly defined areas, with some winners apparently being pre-selected.

All of this eats into the core funding for basic science. The budget of the Russian Foundation for Basic Research (RFBR), the only funding body with a grant system similar to the Western model, was cut sharply last year and will not increase until at least 2014. The average RFBR grant is about US $\$ 12,000$ a year, and even that is in danger - the foundation's council is aiming to increase the number and size of 'innovative' technological projects in only a few areas.

The bureaucratic problems you mention make life difficult for mega-grant holders, but at least they can communicate directly with science minister Andrei Fursenko and even President Dmitry Medvedev. For the less fortunate majority of Russian scientists, these problems make doing science, especially experimental science, almost impossible.

The international community helped Russian science in the 1990s, when collaboration and international grants offered a lifeline for many Russian groups. Now we need the voices of our colleagues around the world to press Russia's scientific leadership into accepting international norms in funding and decision-making, and to clear Russian science of any cronyism and corruption. Mikhail Gelfand

A. A. Kharkevich Institute for Information Transmission Problems, Russian Academy of Sciences, Moscow, Russia. gelfand@iitp.ru

\section{Italian quake: critics' logic is questionable}

The manslaughter case against Italian scientists for inadequately warning local residents before the April 2009 earthquake in L'Aquila, Italy (Nature 477, 264-269; 2011), is not justified.

At the heart of this case lies one fact - the danger to L'Aquila residents at the time of the earthquake. More precisely, what was the chance that a particular individual would be killed in the subsequent 24 hours, given the frequency of low-magnitude tremors around that time and the best available science? That probability, even in L'Aquila's weakest class of building, was estimated at less than 1 in 100,000 on the night of the earthquake (T. van Stiphout et al. Geophys. Res. Lett. 37, L06306; 2010). The occurrence of many little earthquakes does not make the chance of a big earthquake very high.

Conventional wisdom suggests that roughly US $\$ 1$ million needs to be spent on public-safety measures for each life that would be saved. It might have been wise to improve L'Aquila's at-risk buildings, particularly as it has been known for decades that many of them are too weak to withstand earthquakes.

But the hazard level in L'Aquila in the days before the earthquake was insufficient, by two to three orders of magnitude, to justify evacuation of even the weakest buildings. The scientists were right: sitting tight was a good recommendation and, in view of the low risk, all the published quotes from the seismologists were accurate.

The most troubling aspect is the complete absence of a quantitative assessment of risk among the people seeking to condemn the scientists. To critics, it makes no difference whether the likelihood of a magnitude-6.3 earthquake was tiny.

The critics' argument that a sterner warning should have been broadcast is based only on the fact that the event occurred, and so should have been foreseen. This logic seems to lie midway between Monty Python and Franz Kafka, and is terrifying to me as the seismologist responsible for monitoring the US Pacific Northwest, an area inhabitated by 10 million people. John E. Vidale University of Washington, Seattle, USA. vidale@uw.edu

\section{Italian quake: science rides politics}

As you report, the case against Italy's National Commission for Forecasting and Predicting Great Risks hinges not on its inability to forecast the magnitude-6.3 earthquake that struck L'Aquila in April 2009, but on its provision of "incomplete, imprecise and contradicting information" (Nature 477, 264269; 2011). The case highlights a central problem in Italy - the incestuous relationship between science and politics.

To some, the commission seemed more interested in pacifying the local population than in giving clear advice about earthquake preparedness.

When the American Geophysical Union and the American Association for the Advancement of Science issued statements in support of the indicted Italian scientists, I pointed out to these organizations that the international scientific community should be made aware of the real content of the indictment made by attorney Fabio Picuti before they sent statements of support to President Giorgio Napolitano. Otherwise, it would appear that the scientific community was trying to influence the Italian president on the basis of a false premise.

In Italy, a conflict of interest between some scientists and politics is the norm. In too many cases, scientists prefer to go along with, and even to defend, political decisions, rather than to act independently. Examples of this include the building of the largest civil hospital in southern Italy on the slope of Mount Vesuvius (G. Rolandi J. Volcanol. Geotherm. Res. 189, 347-362; 2010), and plans to dispose of radioactive waste near the southern town of Scanzano Jonico - a seismic area near oil and gas fields, where the water table is close to the surface (B. De Vivo Geologia dell'Ambiente Anno XII 2, 1-8; 2004). Both cases proceeded with the support or silence of most of the Italian scientific community. There are many other such cases.

I strongly believe that scientists should clearly explain the limits of their knowledge to the public. They must provide leadership and not patronize. The most important goal has to be the protection of human life. Benedetto De Vivo University of Naples Federico II, Naples, Italy. bdevivo@unina.it

CONTRIBUTIONS

Correspondence may be submitted to correspondence@nature. com after consulting the author guidelines at http:// go.nature.com/cmchno. Readers are also welcome to comment online on anything published in Nature: www.nature.com/nature. 